\title{
ANÄLISE DOS RESULTADOS DA PESQUISA DA INFECÇĀO TUBERCULOSA E DO PRIMEIRO PROGRAMA DE VACINAÇÃO PELO BCG INTRADERMICO EM ESCOLARES DE SÃO PAULO, BRASIL, 1971-1974
}

Diogenes Augusto Certain * Cornélio Pedroso Rosenburg ** Marilia Belluomini*

Roberto Brólio*

Geraldo Chaves Salomon*

RSPU-B/254

Certain, D.A. et al. - Análise dos resultados da vesquisa da infecção tuberculosa e do primeiro programa de vacinação pelo $B C G$ intradérmico em escolares de São Paulo, Brasil, 1971-1974. Rev. Saúde públ., S. Paulo, $9: 125-36,1975$.

RESUMo: São apresentados os resultados do programa de pesquisa da sensibilidade tuberculínica e de vacinação pelo $B C G$ intradérmico em escolares da primeira série da Rede Municipal de Ensino de São Paulo, no período de 1971 a 1974. A pesquisa tuberculinica através da aplicação do PPD, Rt-23, $2 U T$, revelou, nos diferentes anos, coeficientes variando de 6,6 a $7,6 \%$ de reatores fortes e de 1,6 a 3,0\% de reatores fracos. A vacinação pelo $B C G$ intradérmico foi feita em 129.784 crianças, correspondendo a 89,7\% dos 144.641 não reatores. o reteste tuberculinico feito em amostra de escolares vacinados, apresentou percentuais anuais de viragem variando de 85,6 a $96,1 \%$. Destes, 7,8 a $21,4 \%$ reagiram fracamente e 64,2 a $88,3 \%$ reagiram fortemente. Os objetivos foram alcançados, o que se pode observar pelos resultados apresentados observando receptividade do programa por parte da populaço trabalhada.

UnItermos: Tuberculose. Vacinação BCG, intradérmico. Escolares, São Paulo, Brasil. Teste Tuberculinico.

\section{IN T ROD U C A O}

A pesquisa da infecção tuberculosa pelo teste tuberculínico é recurso operacional consagrado em Saúde Pública, empregado para avaliar a extensão da infecção específica na população.
Em 1969, a Divisão Nacional de Tuberculose (DNT), então Serviço Nacional de Tuberculose (SNT), programou a realização de uma pesquisa de caráter progressivo, visando o levantamento da

* Da Disciplina de Tisiologia do Departamento de Epidemiologia da Faculdade de Saúde Pública da USP - Av. Dr. Arnaldo, 715 - São Paulo, SP - Brasil

Da Disciplina de Higiene da Criança do Departamento de Prática Médica em Saúde Pública da Faculdade de Saúde Pública da USP - Av. Dr. Arnaldo, 715 - São Paulo, SP -

* Brasil; e do Departamento de Assistência ao Escolar da Prefeitura Municipal de Sāo Paulo. Rua Pedra Azul, 314 - São Paulo, SP - Brasil 
CERTAIN, D.A. et al. - Análise dos resultados da pesquisa da infecção tuberculosa e do prımeiro programa de vacinação pelo BCG intradérmico em escolares de São Paulo, Brasil. 1971-1974. Rev. Salide pibl., S. Paulo, 9:125-36. 1975.

prevalência da infecção tuberculosa em escolares das capitais brasileiras. com início previsto para 1970 *.

Esse programa foi cumprido em 7 capitais, dele participando crianças matriculadas na primeira série das escolas públicas de Manaus, Belém, Fortaleza, João Pessoa, Recife, Curitiba e São Paulo ".

Em seis capitais os entendimentos foram estabelecidos com as Secretarias Estaduais de Saúde e em São Paulo com a Disciplina de Tisiologia (DT) da Faculdade de Saúde Pública da Tniversidade de São Paulo:

Va esteira do cadastramento tuberculínico. a DNT resolveu instituir paralelamente um outro programa, o "Ensaio Controlado com a Vacina BCG", a ser administrada por via intradérmica (BCGid) em crianças não reatoras ao teste tuberculinico "

Em cada uma das sete capitais. mil escolares foram sorteados: 800 foram vacinados e 200 mantidos como testemunho recebendo placebo pela mesma via de administração.

Em São Paulo. esse ensaio foi realizado em escolares da l. $^{\text {a }}$ série de Escolas Públicas da Rede Estadual de Ensino, evidenciando a viabilidade do método em Saúde Pública pela facilidade de administração e perfeita aceitação por parte da população trabalhada ${ }^{1.2}$.

Tendo o ensaio controlado de vacinação, realizado em 1970. mostrado a sua exeqüibilidade, ele se constituiu em sólido esteio para a DNT planejar a implantação da vacinação BCG-id. em escala nacional, a partir de 1971.

Nesse ano, embora contando com a txperiência anterior e com o mesmo apoio da DNT não foi possível a DT articularse com os órgãos estaduais, isto é, com as Secretarias de Saúde e de Educação de São Paulo.

Nessa ocasião foi a DT procurada pelo Departamento de Assistência Escolar da Prefeitura Municipal de São Paulo (EA), o qual tendo conhecimento dos resultados do cadastro tuberculínico e do ensaio com o BCG-id por ela realizados em 1970). manifestou interesse em desenvolver $1 \mathrm{~m}$ programa similar em toda a Rede Municipal de Ensino.

Logo após os primeiros contatos ficou evidenciado que o citado Departamento não possuia infra-estrutura para, isoladamente, levar a cabo a programação. Dessa constatação, verificou-se a possibilidade de sua imediata implantação desde que providências fossem tomadas no sentido de utilizar a soma de recursos orjginários de ambos os Serviços.

Acertados os entendimentos, foi estabelecido um plano de coordenação e preparação de técnicos de acordo com as normas elaboradas a recomendadas pela DNT".

Os objetivos visados rom a exerução do programa foram:

- conhecer a cueficiente de infecção t11berculosa entre os alunos da $10^{a}$ série das Escolas da Rede Muniripal de Ensino de São Paulo, através do levantamento da prevalência da infer:ção tuberculosa;

- vacinar as crianças não reatoras. $10 m$ ! BCC,-id. a partir de 1971.

Estabelecidos os objetivos, foi constituída a equipe de trabalho para a execução do programa sob a coordenação do professor titular da DT, e do atual professor responsável pela Disciplina de $\mathrm{Hi}$ giene da Criança da Faculdade de Saúdr Pública da L'SP, com a participação de integrantes da DT e pessoal técnico.. auxiliar do EA.

\section{MATERIAL E METODOS}

() pessoal previamente treinado para a aplicação dos testes tuberculínicos e vacinação pelo BCG-id, utilizou material padronizado e observou rigorosamente as normas e térnicas divulgadas pela DNT! 
CERTAIN, D.A. et al. - Análise dos resultados da pesquisa da irifeccāo tuberculosa e do primeiro programa de vacinação pelo BCG intradérmico em escolares de São Paulo. Brasil, 1971-1974. Rev. Saúle puibl., S. Paulo, 9:125-36. 1975.

Para a prova tuberculínica foi empregado o PPD-Rt-23, do Staten Seruminstitut, diluído pela Unidade de Tuberculina do Laboratório de Referência da "Campanha Nacional contra a Tuherculose", na dose de $0,04 \mathrm{mcg}$ por $0,1 \mathrm{ml}$ (2 LT).

O BCG utilizado em 1971 foi o liofilizado de procedência inglesa (Laboratório Glaxo) e fornecido pela DNT; a partír de 1972, a vacina utilizada foi de origem brasileira, produzida pelo "Instituto Ataulfo de Paiva" e distribuída pela DNT, sendo que em 1972 foi apresentada sob a forma líquida e, em 1973 e 1974. sob a forma liofilizada.

Os testes pós vacinais (retestes) foram feitos entre a 8. ${ }^{\mathrm{a}}$ e 12 . $^{\mathrm{a}}$ semanas após a aplicação da vacina, em $10 \%$ dos vacinados para a verificação da viragem tuherculínica, de acordo com o critério de amostragem divulgado pela DNT.

A população escolar assinalada pelos registros. abrangeu 194.415 alunos matriculados na $1 .^{\text {a }}$ série da referida rede de ensino nos anos de 1971 a 1974.

() trabalho de campo foi executado nos próprios estabelecimentos de ensino, no correr do ano letivo, nas salas de aula ou locais previamente determinados.

() escolares com reações positivas foram encaminhados para exames complementares aos Serviços de Tisiologia dos Centros de Saúde, das áreas correspondentes ao local de suas residências.

Considerando-se que a vacinação $\mathrm{BCC}$ por via intradérmica era praticamente desconhecida da população, foram desenvolvidas atividades educativas, em uma primeira fase à equipe executiva, e numa segunda às autoridades escolares, a fim de aproveitar a Escola como importante elemento de ligação entre a equipe e a comunidade. tornando mais fácil a ahordagem dos pais. responsáveis e alunos.

\section{RESULTADOS}

()s resultados gerais são apresentados na Tabela 1. Otrenva-se que as escolas aumentaram de 218 em 1971. para 244 em 1974. Neste período foram registrados 194.415 alunos de 1 la $^{\text {a }}$ série. Pode-se notar que emhora o rúmero de escolas tenha progressivamente aumentado, o número de alunos diminuiu. Assim, em 1971. foram registrados 64.821 alunos, tendo haixado esse número para 43.932 em 1972. mantendo-se mais ou menos estável nos anos subseqüentes. Esta diferença deveu-se ao fato de que no $10^{\circ}$ ano de trabalho foram registrados todos os alunos da $1 .^{2}$ série e a partir de então apenas os novos, excluindo-se os repetentes. Sobre 194.415 alunos, foran aplicados os testes tuberculínicos em 173.300. ou seja, $89.1 \%$. A perda de 21.115 escolares decorreu de fatores tais como: faltas. desistências e transferências para outra rede de ensino. Dos 173.300 testes aplicados, foram lidos 159.529, ou seja. 92.1\%. Observa-se que em todos esses anos houve uma uniformidade de produção da equipe, mantendo uma cobertura de cer(a) de $89.0 \%$ quanto aos testes aplicados e em torno de $92 \%$ quanto aos testes lidos. em cada ano. A leitura revelou a existência de $144.641(90.7 \%$ ) não reatores e $14.888(9.3 \%)$ reatores. Destes, $3.530(2,2 \%)$ reagiram fracamente " $11.358(7.1 \%)$ reagiram fortemente à prova tuberculínica. A distribuição de reatores fracos no período trabalhado revela um aumento crescente. pois de $1,7 \%$ em 1971 atingiu $3 \%$ em 1974. Esta variação não é percehida com a mesma evidência en relação aos reatores fortes quc apenas em 1971 apresentaram um percentual mais haixo 6,6 , sendo que nos demais anos mostra percentuais de 7,$6 ; 7,3$ e 7.2. Do total de 144.641 alunos não reatores, foram vacinados 129.784 , ou seja. $89.7 \%$. Considerando-se os percentuais hastante uniformes nos anos de 1972 , 1973 e 1974, verifica-se que o de 1971, sensivelmente mais baixo. veio interferir no resultado global. A explicação do porquê se encontra na descrição da Tabela :. 
CERTAIN, D.A. et al. - Análise dos resultados da pesquisa da irifeccão tuberculosa e do primeiro programa de vacinaşa pelo BCG intradérmico em escolares de São Paulo, Brasil. 1971-1974. Rer. Sunde pibl., S Paulo, 9:125-36, 1975.

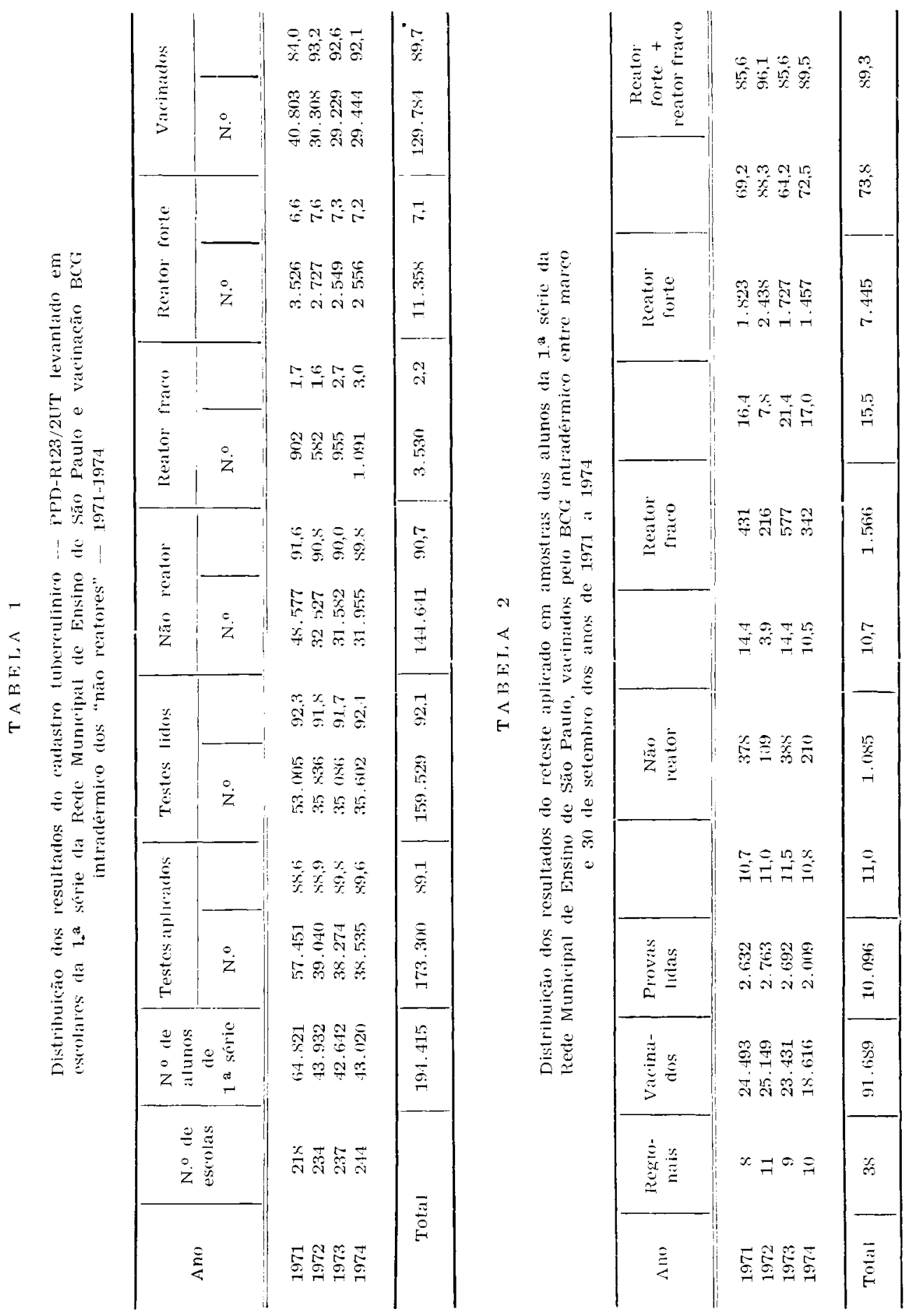




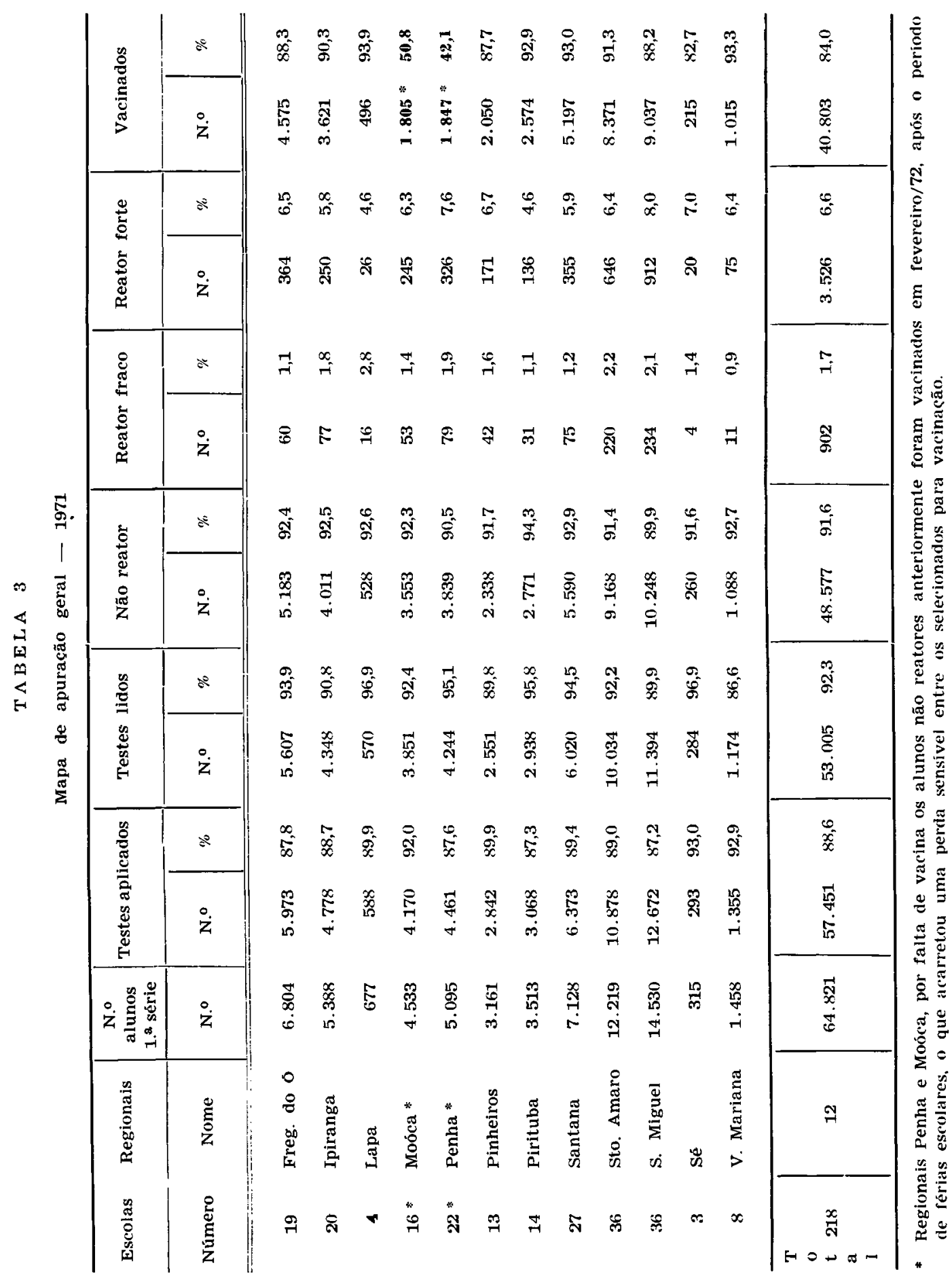




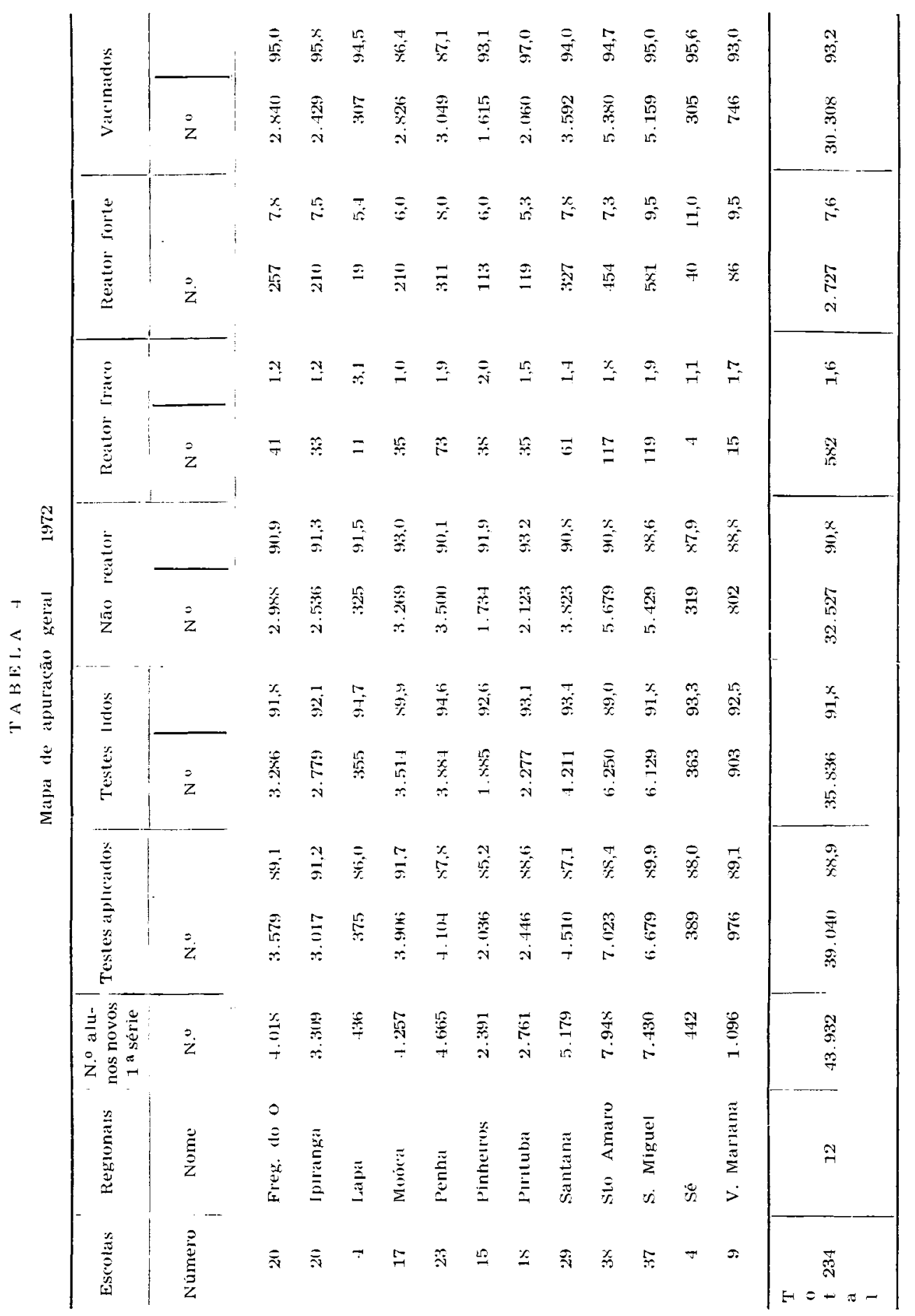


CERTAIN, D.A. et al. - Análise dos resultados da pesquisa da infecção tuberculosa e do primeiro programa de vacinação pelo BCG intradérmico em escolares de são Paulo. Brasil, 1971-1974. Rev. Sañle pribl., S Paulo, 9:125-36, 1975.

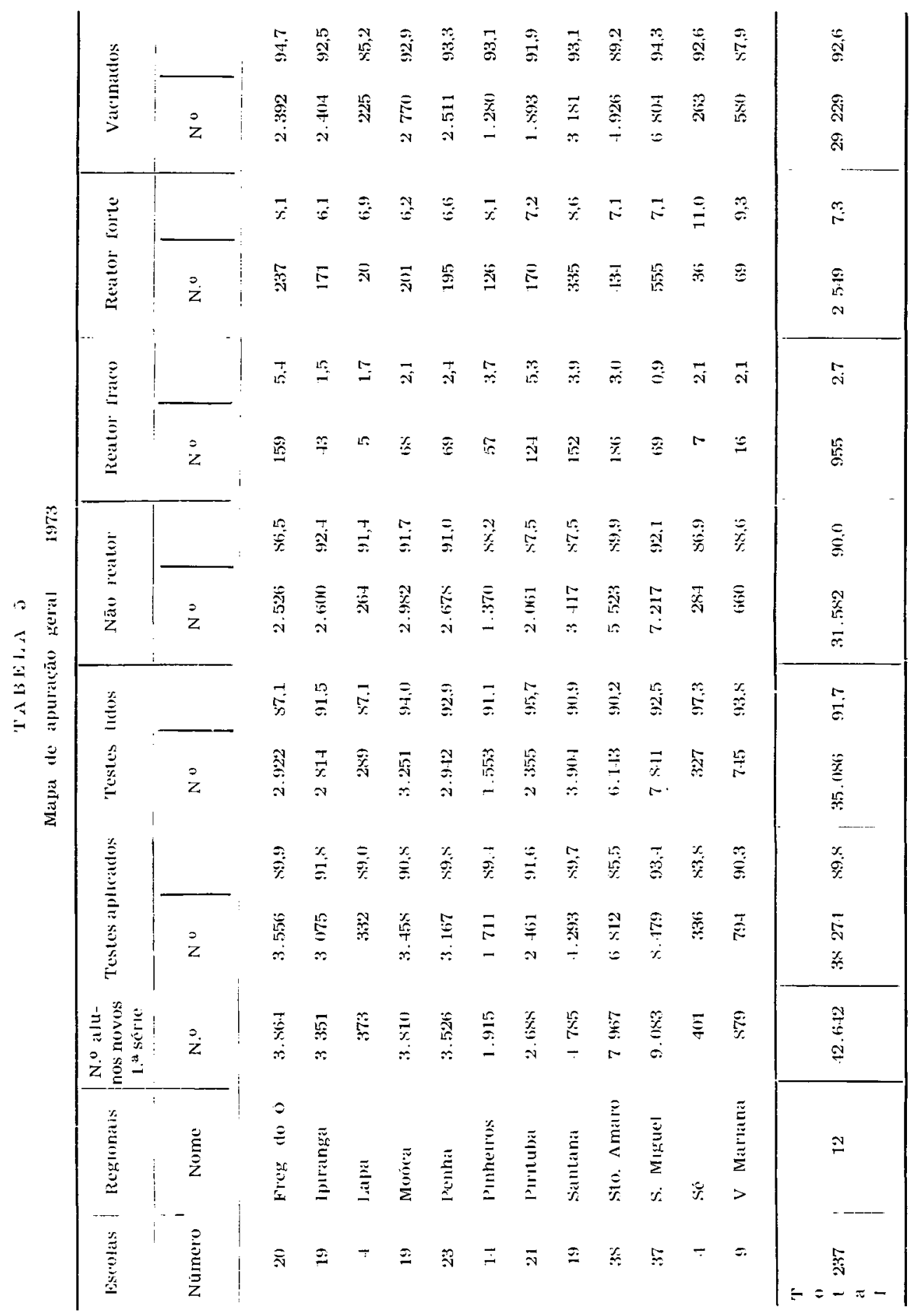


CERTAIN, D.A. et al. - Análise dos resultados da pesquisa da infecção tuberculosa e do primeiro programa de vacinação pelo BCG intradérmico em escolares de São Paulo, Brasil. 1971-1974. Rev. Saude pibl., S. Paulo, 9:125-36, 1975.

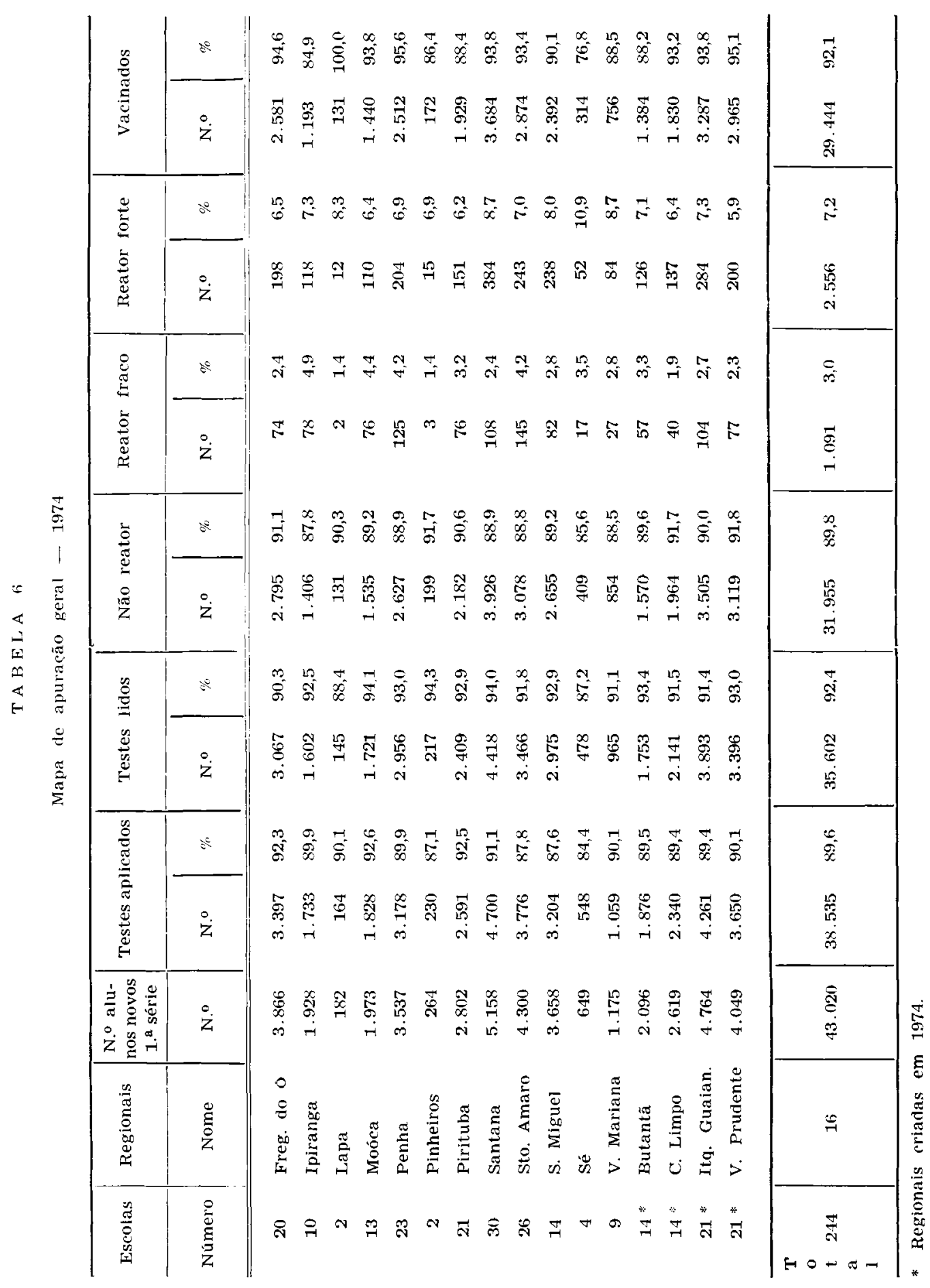


CERTAIN, D.A. et al. - Análise dos resultados da pesquisa da irfeção tuberculosa e do primeiro programa de vacinação pelo BCG intradérmico em escolares de são Paulo, Brasil, 1971-1974. Rev. Saúde públ., S. Paulo, 9:125-36, 1975.

Na Tabela 2, são apresentados os resultados do reteste aplicado em amostras selecionadas por sorteio de mais de $10 \%$ dos alunos da $1 .^{\circledR}$ série, vacinados pelo BCG-id, nos períodos de março a 30 de setembro dos anos de 1971 a 1974. A delimitação desses períodos, de março a setembro, decorreu da necessidade de se atender às normas da DNT que recomendavam a aplicação do reteste entre a $8 .^{\text {a }}$ e $12 .^{2}$ semanas após a vacinação. As avaliações feitas a partir de outubro alcançariam o período de férias. Deste fato, resultou a não coincidência entre o número de Regionais constantes da Tabela 2 e o número efetivo das mesmas (Tabelas 3,4 , 5 e 6).

De acordo com esse critério, o reteste processou-se em 10.096 escolares, 11\% dos 91.689 não reatores, vacinados até 30 de setembro dos anos de 1971 a 1974.

Da população submetida a nova prova tuberculínica, $1.085(10,7 \%)$ conservaram-se não reatores e $9.011(89,3 \%)$ mostraram viragem tuberculínica sendo que $1.566(15,5 \%)$ com reação fraca e $7.445(73,8 \%)$ com reação forte.

Lm comportamento peculiar mostrou o reteste realizado em 1972 quando apenas $109(3,9 \%)$ crianças não reagiram à tuberculina e $2.654(96,1 \%)$ tornaram-se reatoras com a seguinte distribuição: $216(7,8 \%)$ fracos e $2.438(88,3 \%)$ fortes.

Nas Tabelas 3, 4, 5 e 6 , correspondentes a cada ano de 1971 a 1974 , estão discriminados os resultados da programação por número de Escolas de acordo com a Administração Regional a qual pertencem. Nos 3 primeiros anos não houve modificação quanto ao número de Regionais. Na Tabela 6 surgem 4 novas, a saber: Butantã, resultante do desdobramento da Regional de Pinheiros; Campo Limpo, do desdobramento da Regional de Santo Amaro; Itaquera-Guaianazes, do desdobramento da Regional de São Miouel, e. Vila Prudente, da reunião de partes das Regionais da Penha. Moóca e Ipiranga.
Na Tabela 3, observa-se queda sensivel nos percentuais referentes aos alunos vacinados nas Regionais da Penha e Moóca. Esta queda ocorreu devida a falta de vacina disponível para a vacinação dos não reatores de 1971 daquelas Regionais. Com a vinda da vacina em princípios de 1972, somente os alunos selecionados no ano anterior que puderam ser identificados tomaram o BCG. De um total de 7.392 não reatores, das 2 Regionais, apenas 3.652 crianças foram vacinadas. Se não fora esta deficiência a cobertura de 1971 atingiria $90,2 \%$, ao contrário dos $84 \%$, apresentados na Tabela 1 .

\section{COMENTARIOS}

A execução do programa, sem alterações, durante 4 anos sucessivos, na Rede Municipal de Ensino do Município de São Paulo, evidenciou certos pontos que não podem deixar de ser registrados:

Em primeiro lugar, a rentabilidade operacional conseguida, mostra como um modelo a exequiibilidade de programas similares.

0 estudo da infecção tuberculosa, de acordo com um levantamento das escolas agrupadas por Regiões, revela de maneira clara, que há manchas epidemiológicas sugestivas de maior prevalência de casos de tuberculose, independente de sua situação urbana, intermediária ou periférica. De acordo com esse levantamento os não reatores não apresentam alterações muito sensíveis em seus percentuais. uma vez que eles permanecem mais ou menos estáveis. Quanto aos reatores fortes, que revelam significativamente a presença provável da doença em focos domiciliares ou vizinhos ${ }^{\top}$, as alterações são significativas, como pode ser observado nas Regionais de São Miguel (zona periférica), Santana e Vila Mariana (zona intermediária) e Sé e Lapa (zona urhana). Nesta última, os coeficientes de reatores fortes rêm aumentando progressiva- 
CERTAIN, D.A. et al. - Análise dos resultados da pesquisa da infecção tuberculosa e do primeiro programa de vacinação pelo BCG intradérmico em escolares de São Paulo, Brasil, 1971-1974. Rev. Saúde públ., S. Paulo, 9:125-36, 1975.

mente em cada ano. Portanto, não há porque se considerar a posição epidemiológica do município como um todo. Diante destas consideraçōes, poderemos com relativa segurança, individualizar as áreas prioritárias em termos de luta contra a tuberculose.

Os reatores detectados durante os 4 anos foram objeto de especiais cuidados em termos do encaminhamento para os Serviços de Tisiologia das Unidades Sanitárias. Mercê do preparo das equipes de campo e do pessoal da escola, foi possível obter-se o registro do comparecimento de aproximadamente $60 \%$ desses reatores aos respectivos Serviços de Tisiologia. Merece citação especial a participação das famílias dos reatores, que sistematicamente convocadas pelas escolas, compareceram às reuniôes, que se realizaram com o fim específico de esclarecê-las sobre o significado das reações positivas e a importância do encaminhamento para os serviços especializados. Educadoras sanitárias do EA, verificaram o comparecimento e a atenção médica propiciada a esses reatores. Durante os 4 anos, pôde-se observar que mais de $90 \%$ dos alunos reatores foram regularmente submetidos a exame radiológico. Entretanto, não se pôde observar uma conduta uniforme em todos os Serviços de Tisiologia, no que diz respeito a indicação de quimioterapia ou quimioprofilaxia.

Estes comentários reafirmam a necessidade de integração e da uniformidade de conduta dos Serviços de Tisiologia das Unidades Sanitárias para atender a qualquer programa de controle da tuberculose.

$O$ coeficiente médio diáric de absenteísmo escolar na Rede Municipal de Ensino, da ordem de $10 \%$ *, ocasionou uma abrangência menor em termos de cobertura vacinal, duplicada pela necessidade de operações em dias distintos, a saber: teste tuberculínico e subseqüente vacina- ção dos não reatores. Este problema em parte será minorado com as novas recomendações da DNT em termos nacionais, que preconiza a vacinação indiscriminada, sem teste prévio a partir de 1975.

No Centro de Saúde da Faculdade de Saúde Pública, foi centralizado o controle das complicações vacinais. Assim, foram as famílias orientadas no sentido de encaminhar ao Serviço de Tisiologia dessa Unidade toda a criança cuja evolução da vacina fosse motivo de qualquer preocupação. Em todo o período estudado não se verificou a ocorrência de reações indesejáveis ou de difícil solução. Também não foi constatada a presença de quelóide entre as crianças vacinadas.

No decorrer dos trabalhos, houve a coincidência de outras imunizações se desenvolvendo simultaneamente com o programa. Nada de extraordinário ocorreu com a aplicação da vacina anti-tetânica e anti-meningítica antes ou após a aplicação do BCG-id ${ }^{9,10}$.

Outro aspecto importante e que merece ser destacado é o que se refere ao uso do produto liofilizado e líquido da vacina. No ano de 1971 , foi utilizada na programação a vacina "Glaxo" liofilizada e que se comportou em termos de alergização como a liofilizada brasileira, produzida na Fundação Ataulfo de Paiva e utilizada em 1973 e 1974.

No ano de 1972, em que a vacina empregada foi a líquida, também fornecida pela Fundação, os resultados do reteste (Tabela 2) foram bem superiores o que até certo ponto está de acordo com os trabalhos que mencionam as perdas dos germes vacínicos liofilizados em seu preparo para a aplicação ${ }^{9,10}$.

Isto posto, é de se admitir que nos locais onde a vacina liquida possa ser utilizada logo após o seu recebimento com a conservaçáo e obediência ao prazo de validade observados rigorosamente, seria

* Relatório de Atividades do Departamento de Assistencia Escolar da Prefeitura Municipal de São Paulo, 1970. 
CERTAIN, D.A. et al. - Análise dos resultados da pesquisa da irifecção tuberculosa e do primeiro programa de vacinação pelo BCG intradérmico em escolares de São Paulo, Brasil. 1971-1974. Rev. Saúde públ., S. Paulo, 9:125-36, 1975.

de vantagem o seu emprego em lugar da liofilizada.

A partir de 1975, de acordo com a programação da DNT para as escolas brasileiras, o Estado de São Paulo irá, como os outros, promover a vacinação indiscriminada nos escolares de todas as séries.

No próximo ano as atividades programadas para as áreas Municipal e Estadual irão se desenvolver nos mesmos moldes cobrindo, indiscriminadamente, com a vacinação, todos os alunos matriculados pela primeira vez e na primeira série.

Dada a importância dos dados epide- miológicos relativos a infecção tuberculosa e sua evolução na idade escolar, a DNT recomendou a reserva de alunos para constituição de uma amostra destinada ao cadastro tuberculínico.

Os resultados do programa desenvolvido nestes quatro anos evidenciou, em primeiro lugar, sua aceitação pela comunidade e, em segundo, a par de informaçôes importantes para o conhecimento epidemiológico da infecção tuberculosa. mostrou também numa demonstração irretorquível, a viabilidade da vacinação intradérmica como medida de Saúde Pública.

RSPU-B/254

CERTAIN, D.A. et al. - [Data analysis of the tuberculous infection investigation and of the first programme of vaccination with intradermic BCG among schoolchildren in S. Paulo, Brazil: 1971 to 1974]. Rev. Saúde públ., S. Paulo, 9:125-36, 1975 .

SUMMARY: The results of tuberculinic sensitivity investigation and vaccination of the non reactors with intradermic $B C G$ among schoolchildren in the first grades of the $\mathbf{S}$. Paulo Municipal Schools over a period of four years is presented. The data obtained showed rates that varied between 1.6 and $3.0 \%$ for weak reactors and 6.6 and $7.6 \%$ for strong reactors. Vaccination was performed on 129,784 children, corresponding to $89.7 \%$ of the 144,641 non reactors. The investigation of the tuberculinic turn-over after vaccination was done by sampling and showed, throughout the years, rates which varied from 85.6 to $96.1 \%$ of convertees. Of these, 7.8 to 21.4 showed weak reactions and 64.2 to $88.3 \%$, strong reactions. These data give some important informations on the epidemiological situation of Tuberculosis among us and demonstrate the viability of vaccination with intradermic BCG as a measure of Public Health.

UNITERMs: Tuberculosis. BCG vaccination. Schoolchildren, S. Paulo, Brazil. Tuberculin test.

\section{REFERENCIAS BIBLIOGRÁFICAS}

1. CERTAIN, D.A. et al. - Ensaio de BCG intra-dérmico em escolares de São Paulo, Capital, 1970. Rev. Div. nac Tuberc, 15:218-27, 1971

2. CERTAIN, D.A. - Medidas para a introdução do BCG intra-dérmico no Brasil. Rev, Div. nac. Tuberc., 14: 313-22, 1970.

3. CERTAIN. D.A, et al - Planejamento de um programa de rastreamento tuberculínico em escolares do primeiro ano das Escolas Públicas Estaduais de São Paulo, 1970 (Apresentado ao Congresso Nacional de Tuberculose, 16. ${ }^{\circ}$. João Pessoa, Paraiba, 1972 ).

4. DIVISAO NACIONAL DE TUBERCULOSE - Levantamento da prevalencia da infeccio tuberculosa e vacina- 
CERTAIN, D.A. et al. - Análise dos resultados da pesquisa da infecção tuberculosa e do prímeiro programa de vacinação pelo BCG intradérmico em escolares de São Paulo, Brasil, 1971-1974. Rev. Saúde públ., S. Paulo, 9:125-36, 1975.

cão $B C G$ intradérmica em escolares. Rio de Janeiro, 1971. Mimeografado.

5. LINS DE LIMA, L. et al. - Ensaio de vacinação BCG intra-dérmica em escolares das Capitais brasileiras. Rev. Div. nac. Tuberc., 17:434-45, 1973.

6. PAZ DE ALMEIDA, A. - Prevalência da infecção tuberculosa em escolares das Capitais brasileiras. Rev. Div. nac. Tuberc. 17:155-74, 1973.

7. SEMINÁRIO REGIONAL DE TLBERCULOSIS - Maracay, Venezuela. 1964. Informe final e documentos de trabajo. Washington, D.C., Organizacion Panamericana de la Salud, 1965. (Publ, cient., 112)
8. SERVIÇO NACIONAL DE TUBERCULO$\mathrm{SE}$ - Levantamento da prevalência la infeccúo tuberculosa em escolares das capitais brasileiras. Rio de Janeiro, 1970. Mimeografado.

9. TOMAN, $\mathrm{K}$. - Estado atual de los conocimientos tecnicos sobre la Imunization contra la tuberculosis. Bol. ofic. sanit. panamer., $75(2): 92-111$, 1973.

10. WORLD HEALTH ORGANIZATION Expert Committee on Tuberculosis. $9^{\text {th }}$ Session, Geneva, 1973. TB/WP/ 73.7. Mimeografado.

Recebido para publicacio em 14-0.3-1975 A provado para publicasão em 04-04-1975 